Abstract AB0997 Table 1. Comparison of TOC patients and matched controls. Baseline parameters and adverse events are listed. *Number and rate of patients are given. \# t-test or $\chi 2$-test as appropriate

\begin{tabular}{|l|c|c|c|}
\hline & $\begin{array}{c}\text { TOC cohort } \\
\mathrm{N}=88\end{array}$ & $\begin{array}{c}\text { Matched } \\
\text { controls } \\
\mathrm{N}=88\end{array}$ & P-value\# \\
\hline Baseline Parameters & & & \\
\hline Gender female, n (\%) & $73(82.9)$ & $67(76)$ & 0.35 \\
\hline Age onset, mean (SD), years & $7.5(4.6)$ & $7.5(4.7)$ & 0.89 \\
\hline Disease duration, mean (SD), years & $5.2(4.4)$ & $2.9(2.8)$ & $\mathbf{0 . 0 0 0 1}$ \\
\hline RF neg. poly-JIA, n (\%) & $57(64.8)$ & $62(70.5)$ & 0.52 \\
\hline RF pos. poly-JIA, n (\%) & $10(11.4)$ & $10(11.4)$ & 1.0 \\
\hline Extended Oligo-JIA, n (\%) & $21(23.9)$ & $16(18.2)$ & 0.46 \\
\hline Pre-treatment with biologics, n (\%) & $70(79.5)$ & $12(13.6)$ & $<0.0001$ \\
\hline Active joint count, mean (SD) & $7.3(7.4)$ & $7.4(5.9)$ & 0.92 \\
\hline CHAQ DI, mean (SD) & $0.65(0.63)$ & $0.66(0.66)$ & 0.92 \\
\hline CRP, mg/l, mean (SD) & $8.9(18.9)$ & $9.4(18.6)$ & 0.86 \\
\hline JADAS10, mean (SD) & $14.7(6.4)$ & $15.8(6.0)$ & 0.24 \\
\hline Adverse Events & & & \\
\hline Patients with AE, n (\%) & $31(35.2)$ & $34(38.6)$ & 0.75 \\
\hline Patients with SAE, n (\%) & $3(3.4)$ & $1(1.1)$ & 0.62 \\
\hline Patients with infectious AE, n (\%) & $19(21.6)$ & $20(22.7)$ & 1.0 \\
\hline $\begin{array}{l}\text { Patients with medically important } \\
\text { infections, n (\%) }\end{array}$ & $1(1.1)$ & $3(3.4)$ & 0.62 \\
\hline Patients with increased transaminases, n (\%) & $4(4.5)$ & $3(3.4)$ & 1.0 \\
\hline Patients with hyperbilirubinemia, n (\%) & $3(3.4)$ & - & 0.25 \\
\hline Patients with neutro-/leukopenia, n (\%) & $3(3.4)$ & $1(1.1)$ & 0.62 \\
\hline
\end{tabular}

Disclosure of Interests: Ariane Klein: None declared, Dennis Conzelmann: None declared, Toni Hospach Speakers bureau: Chugai, Roche, Novartis, Frank Weller-Heinemann: None declared, Sandra Hansmann: None declared, Jasmin Kuemmerle-Deschner Grant/research support from: Jasmin Kuemmerle-Deschner is an employee of University of Tuebingen, Germany, and received consultants/speakers fees from Novartis and SOBI pharmaceuticals and grant support from SOBI and Novartis., Consultant for: Jasmin Kuemmerle-Deschner is an employee of University of Tuebingen, Germany, and received consultants/speakers fees from Novartis and SOBI pharmaceuticals and grant support from SOBI and Novartis., Speakers bureau: Jasmin Kuemmerle-Deschner is an employee of University of Tuebingen, Germany, and received consultants/speakers fees from Novartis and SOBI pharmaceuticals and grant support from SOBI and Novartis., Michael Borte Grant/research support from: Pfizer and Shire, Kirsten Minden Consultant for: AbbVie, Ivan Foeldvari Consultant for: Chugai, Novartis, Christoph Rietschel: None declared, Gerd Ganser: None declared, Ralf Trauzeddel: None declared, Markus Hufnagel: None declared, Dirk Foell Grant/research support from: not specified, Consultant for: not specified, Speakers bureau: not specified, Rainer Berendes: None declared, Gundula Boeschow: None declared, Prasad Oommen: None declared, Angelika Thon: None declared, Gerd Horneff: None declared DOI: 10.1136/annrheumdis-2019-eular.2750

\section{AB0998 SEVERE IGA VASCULITIS: CYCLOPHOSPHAMIDE IN QUESTION}

Kateřina Kobrová ${ }^{2}$, Lenka Minxová ${ }^{2}$, Jakub Zieg ${ }^{3}$, Sylva Skálová ${ }^{2}$ Pavla Doležalová4. 'Masaryk Hospital, Department of Paediatrics, Ústí nad Labem, Czech Republic; ${ }^{2}$ Faculty of Medicine, Charles University and University Hospital, Department of Paediatrics, Hradec Králové, Czech Republic; ${ }^{3} 2$ nd Faculty of Medicine, Charles University and Motol University Hospital, Paediatric Nephrology Unit, Department of Paediatrics, Prague, Czech Republic; ${ }^{4} 1$ st Faculty of Medicine, Charles University and General University Hospital, Paediatric Rheumatology Unit, Department of Paediatrics and Adolescent Medicine, Prague, Czech Republic

Background: Cyclophosphamide (CYC) has been a mainstay in the treatment of severe childhood primary systemic vasculitis. Although major organ involvement is rare in $\lg A$ vasculitis ( $\lg A V), C Y C$ is among therapeutic options in moderate and severe IgAV nephritis.(1) No specific recommendations are available for cerebral vasculitis of IgAV.

Objectives: To describe disease course and treatment response in 2 patients with severe IgAV with CNS and renal involvement.

Methods: Case reports with disease assessments using Paediatric Vasculitis Activity Score (PVAS).(2)

Results: Both children were Caucasian boys with unremarkable previous history aged 4 (Patient 1) and 8 (Patient 2) years. In both cases the initial typical presentation included purpura and abdominal pain in both, arthritis in Patient 1 and haematuria in Patient 2. After 2 weeks of prednisone therapy for severe gastrointestinal (GIT) symptoms Patient 1 was admitted for right-sided weakness and facial palsy. His brain MR revealed an ischaemic lesion. His PVAS reached 21/63 for skin, abdominal, renal (haematuria) and CNS systems. When Patient 2 was admitted for abdominal symptoms he developed a focal epileptic paroxysm. His brain MRI was compatible with cerebral vasculitis. His nephritic-nephrotic syndrome prompted renal biopsy showing mesangioproliferative nephritis with IgA deposits. His PVAS was $27 / 63$ for skin, abdominal, renal (hypertension, haematuria, proteinuria) and CNS systems. Both patients received 3 doses of intravenous methylprednisolone $30 \mathrm{mg} / \mathrm{kg}$ followed by oral prednisone $1 \mathrm{mg} / \mathrm{kg}$ with subsequent tapering and 3 doses of CYC $500 \mathrm{mg} / \mathrm{m}^{2}$ (monthly i.v.). At follow-up 3 months after the $1^{\text {st }}$ CYC dose both patients fully recovered neurologically. Patient 2 was on prednisone (0.2 $\mathrm{mg} / \mathrm{kg}$ ) and ACE inhibitor and his urine was negative for the first time, PVAS $=0$. Patient 1 had been developing significant proteinuria during prednisone withdrawal and his PVAS counted 10/63 for renal disease. Prednisone was re-instituted and ACE inhibitor added while renal biopsy has been pending.

Conclusion: In both cases therapy with corticosteroids and CYC led to the full recovery of CNS disease but did not prevent progression of nephritis in Patient 1. Response of Patient 2 nephritis to CYC appeared satisfactory at 3 months visit but would require confirmation after full prednisone withdrawal. Although generally benign, when IgAV presents with major organ involvement its treatment is challenging. Further research is needed in order to gather better evidence to support treatment recommendations.

\section{REFERENCES}

[1] Özen S, et al. Europen consensus-based recommendations for diagnosis and treatment of $\lg A$ vasculitis - the SHARE initiative. Rheumatology (Oxford) 2019, in print

[2] Doležalová $P$, et al. Disease activity assessment in childhood vasculitis: development and preliminary validation of the Paediatric Vasculitis Activity Score (PVAS). Ann Rheum Dis 2013 72(10):1628-33

Disclosure of Interests: None declared

DOI: 10.1136/annrheumdis-2019-eular.6731

\section{AB0999 PAEDIATRIC TO ADULT RHEUMATOLOGY CARE}

Brigita Koren, Maja Tomazin, Vojko Berce, Artur Pahor, Iztok Holc. University Medical Centre Maribor, Maribor, Slovenia

Background: Many juvenile onset rheumatic diseases continue to have activity in adulthood. Therefore, a continuous uninterrupted healthcare of these patients is needed.

Objectives: To determine whether and how therapy has changed in patients after transition from paediatric to adult rheumatology service in our medical centre.

Methods: A retrospective single centre study was performed. Patients seen at least once at both paediatric and adult rheumatology outpatient service were enrolled. Data was collected from patients medical records.

Results: A total of 50 patients were included. Most of them were female (82\%). Average age at transition was 19,6 years (range 18- 27 years) Mean time of follow up was 44 months (range 2- 119 months). Juvenile idiopathic arthritis (JIA) was the most common juvenile onset chronic rheumatic disease. The medications used either as monotherapy or in combination before transition at last visit at paediatric rheumatology 
outpatient unit were nonsteroidal anti-inflammatory drugs (NSAIDs) (14\%), corticosteroids $(6 \%)$, synthetic disease modifying antirheumatic drugs (DMARDs) (18\%), biologic DMARDs (2\%).

After transition $34 \%$ of patients used NSAIDs, $16 \%$ corticosteroids, $24 \%$ synthetic DMARDs, $8 \%$ biologic DMARDs.

Without any medication before and after transition were $66 \%$ and $48 \%$ of patients, respectively.

After transition $36 \%$ of patients had their therapy changed. 30\% needed escalation of therapy because their disease was still active or they experienced exacerbation.

Most changes in therapy occurred in the first year after transition.

Conclusion: We confirmed that many patients with juvenile onset rheumatic disease had changes in their therapy after transition, especially escalations of therapy. Most changes occurred in the first year after transition which is a vulnerable period in a young adult life.

\section{REFERENCES}

[1] Foster $\mathrm{H}$, et al. EULAR/PReS standards and recommendations for the transitional care of young people with juvenile- onset rheumatic diseases. Ann Rheum Dis 2017;76:639-46.

[2] Jensen PT, et al. Quantitative evaluation of a pediatric rheumatology transition program. Pediatric Rheumatology 2015; 13:17.

[3] Kanakoudi-Tsakalidou $F$. The art of transitioning pediatric patients with rheumatic diseases to adult rheumatologists. Mediterr $\mathrm{J}$ Rheumatol 2016;27(2):55-8

[4] Luque Ramos A. Transition to adult rheumatology care is necessary to maintain DMARD therapy in young people with juvenile idiopathic arthritis. Semin Arthritis Rheum 2017;47(2):269-75.

Disclosure of Interests: None declared

DOI: 10.1136/annrheumdis-2019-eular.722

\section{AB1000 THE SURVIVAL OF METHOTREXATE IN JUVENILE IDIOPATHIC ARTHRITISCHILDREN AFTER DURING FIRST BIOLOGIC TREATMENT}

Rinat Raupov ${ }^{1}$, Lubov Sorokina ${ }^{1}$, Yuri Korin ${ }^{2}$, llya Avrusin ${ }^{1}$, Elizaveta Orlova ${ }^{3}$, Ekaterina Gaidar ${ }^{1}$, Margarita Dubko ${ }^{1}$, Vera Masalova ${ }^{1}$, Tatiana Likhacheva ${ }^{1}$, Ludmila Snegireva ${ }^{1}$, Eugenia Isupova ${ }^{1}$, Tatiana Kornishina ${ }^{1}$, Olga Kalashnikova ${ }^{1}$, Mikhail Kostik'. ${ }^{1}$ Saint-Petersburg State Pediatric Medical University, SaintPetersburg, Russian Federation; ${ }^{2}$ Peter the Great St.Petersburg Polytechnic University, Saint-Petersburg, Russian Federation; ${ }^{3}$ Pediatric Research and Clinical Center for Infection Diseases, Saint-Petersburg, Russian Federation

Background: Methotrexate (MTX) is a gold standard for treatment of juvenile idiopathic arthritis (JIA) patients. The main adverse events (AE) related to the MTX are intolerance, increased rate of infections, elevation of the liver enzymes, hematological abnormalities and stomatitis, which required to stop the MTX therapy [1]. In children without remission who tolerated MTX often the second-line treatment is the biologics, which may use alone or in the combination with MTX.

Objectives: The aim of our study was to evaluate the main reasons of MTX discontinuation in JIA children who started first biologic.

Methods: In the study were included 173 non-systemic JIA patients, whom biologic therapy was prescribed firstly to previous MTX treatment. We evaluate the main reasons of MTX discontinuation after the starting of the biologic treatment, duration of MTX treatment (all and after biologic start), achievement the remission, according C. Wallace criteria and time to remission, flare of JIA. We compared two groups: i) patients with biologics with ongoing methotrexate and ii) patients with biologics alone, whom MTX was discontinued or not prescribed.

Results: During the trial MTX discontinued 40 (23.1\%) patients: due to intolerance $(n=11)$, other adverse events (AE) $(n=10)$, except intolerance (mainly, frequent infection and transaminitis) and remission of JIA $(n=19)$. Patients with onset age of JIA $<4.4$ years were in the risk of developing MTX intolerance (LogRank test, $\mathrm{p}=0.000001$ ), but the younger patients usually developed other AE. Compare of the three subgroups of patients, who discontinued MTX we have not yet found any differences, except the onset age and frequency of remission, which was higher in patients who discontinued MTX due to other AE than due to intolerance.

Conclusion: The main factor, associated with MTX discontinuation in JIA patients, who received first biologic was the disease onset age. Eldest age was related to higher risk of developing the MTX intolerance.

\section{REFERENCES}

[1] van Dijkhuizen EH, Pouw JN, Scheuern A, Hügle B, Hardt S, Ganser G Kümmerle-Deschner JB, Horneff G, Holzinger D, Bulatović Ćalasan M, Wulffraat NM. Methotrexate intolerance in oral and subcutaneous administration in patients with juvenile idiopathic arthritis: a cross-sectional, observational study. Clin Exp Rheumatol. 2016;34(1):148-54.

Disclosure of Interests: None declared DOI: 10.1136/annrheumdis-2019-eular.5233

\begin{tabular}{|c|c|c|c|c|c|c|}
\hline Parameter & $\begin{array}{c}\text { Still ongoing MTX } \\
(n=133)\end{array}$ & $\begin{array}{c}\text { Intolerance } \\
(\mathrm{n}=11)\end{array}$ & $\begin{array}{l}\text { Other AE } \\
(n=10)\end{array}$ & $\begin{array}{c}\text { Remission } \\
(\mathrm{n}=19)\end{array}$ & $\mathrm{p}$ & $\begin{array}{c}\mathrm{p} \text { for } 3 \text { groups of MTX } \\
\text { discontinuation }\end{array}$ \\
\hline Sex, females, n (\%) & $87(66)$ & $7(64)$ & $7(70)$ & $13(68)$ & 0.99 & 0.95 \\
\hline Uveitis, $\mathrm{n}(\%)$ & $27(20)$ & $1(9)$ & $0(0)$ & $5(26)$ & 0.28 & 0.12 \\
\hline ANA positivity, $\mathrm{n}(\%)$ & $37 / 85(44)$ & $3 / 8(38)$ & $2 / 4(50)$ & $1 / 9(11)$ & 0.29 & 0.28 \\
\hline Onset age, years & $4.8(2.3-10.2)$ & $10.2(5.6 ; 12.7)$ & $2.1(1.5 ; 3.2)$ & $7.2(3.0 ; 9.2)$ & 0.012 & 0.005 \\
\hline CRP & $1.5(0.4 ; 9.2)$ & $3.3(2.4 ; 4.7)$ & $0.9(0.3 ; 1.7)$ & $3.8(1.0 ; 9.1)$ & 0.22 & 0.06 \\
\hline Active joints, $n$ & $3.0(2.0 ; 7.0)$ & $2.0(2.0 ; 5.0)$ & $2.5(1.0 ; 9.0)$ & $3.0(1.0 ; 5.0)$ & 0.63 & 0.97 \\
\hline Time before biologics, years & $2.7(1.1 ; 6.0)$ & $3.1(1.4 ; 4.3)$ & $2.1(1.5 ; 7.9)$ & $1.6(0.9 ; 2.8)$ & 0.51 & 0.35 \\
\hline Time before MTX, mo & $12.2(3.6 ; 37.5)$ & $27.3(3.6 ; 43.6)$ & $12.3(5.1 ; 30.7)$ & $6.1(2.0 ; 19.3)$ & 0.39 & 0.41 \\
\hline MTX duration, all, mo & $65.9(42.9 ; 91.3)$ & $27.6(6.8 ; 37.6)$ & $30.9(6.0 ; 35.5)$ & $25.4(14.6 ; 39.5)$ & 0.00001 & 0.97 \\
\hline $\begin{array}{l}\text { MTX duration after biologics, } \\
\text { mo }\end{array}$ & $54.2(32.1 ; 65.8)$ & $12.3(7.8 ; 16.2)$ & $11.3(5.8 ; 12.5)$ & $14.7(5.3 ; 25.9)$ & 0.00001 & 0.74 \\
\hline Remission, n (\%) & $82 / 130(63)$ & $7(64)$ & $9(90)$ & $19(100)$ & 0.006 & 0.015 \\
\hline Remission duration, mo & $14.6(6.3 ; 36.3)$ & $16.1(9.6 ; 45.1)$ & $9.8(3.9 ; 20.2)$ & $10.5(4.8 ; 39.6)$ & 0.43 & 0.41 \\
\hline Flare, $\mathrm{n}(\%)$ & $55 / 129(43)$ & $5(46)$ & $0(0)$ & $7(37)$ & 0.06 & 0.04 \\
\hline
\end{tabular}

